\title{
Ocorrência de custos ocultos em operações de serviços: insights sobre observação em uma sociedade de economia mista no Brasil
}

\author{
Occurrence of hidden costs in service operations: \\ insights into a publicly held company
}

\author{
Paulo César Pereira da Silva ${ }^{1}$ \\ Cosmo Severiano Filho'
}

\begin{abstract}
Resumo: A otimização dos processos e os melhoramentos contínuos dependem, em sua grande maioria, da gestão desenvolvida em relação ao reconhecimento, verificação e mensuração dos custos desprendidos e gerados através dos fatores de produção, para obtenção do produto final. O objetivo principal deste artigo é verificar a ocorrência de custos ocultos no processo da prestação de serviços, numa sociedade de economia mista com controle estatal do Estado da Paraíba. A verificação dos custos ocultos ocorridos na entidade foi efetuada, principalmente, em relação aos disfuncionamentos organizacionais mais frequentes do tipo: espera, movimentação inútil, sobressalários, sobreconsumo, retrabalho, acidente de trabalho, absenteísmo, ociosidade e litígios. Essa verificação constou de questionamentos junto aos operadores dos postos de trabalho, por meio de questionários semiestruturados, bem como a observação in loco no desenvolvimento de suas funções. Pretende-se chamar a atenção para a existência de custos ocultos não contabilizados pelos sistemas tradicionais de custeamento, bem como para sua intangibilidade não reconhecida pelos diversos modelos de métricas da produtividade, a exemplo do Modelo Soniano (SON, 1991). A abordagem utilizada em custos ocultos neste artigo foi realizada com base na fundamentação teórica desenvolvida por Savall e Zardet (1991). Os resultados da pesquisa apontaram para a ocorrência de custos ocultos originados, principalmente, em razão de disfuncionamentos ligados ao retrabalho, esperas, alta rotação de pessoal e stress. Ficou evidenciado ainda que, dos custos ocultos mais frequentes observados na sociedade de economia mista, os que contribuem mais fortemente para o não funcionamento adequado da organização são os retrabalhos e as esperas, verificados em quase todos os setores.
\end{abstract}

Palavras-chave: Custos. Custos ocultos. Operações de serviços.

\begin{abstract}
Optimization and the continuous improvement of processes are highly dependent on the management of actions related to identification, checking, and measurement of the costs generated during the production of the final product. The main objective of this article is to verify the occurrence of hidden costs of services rendered by a public company controlled by the Paraiba State government in Brazil. The occurrence of hidden costs incurred by this corporation was verified in terms of the most common organizational malfunctioning such as: waiting time, useless motion, overpay, overconsumption, rework, occupational accidents, absenteeism, idleness, and litigations. This study was based on semi-structured interviews conducted with workstation operators and in loco observation of workers' activities. It is important to highlight the occurrence of hidden costs that are not accounted by the traditional cost systems and their intangibility, which is not recognized by productivity measurement models, for example, the Soniano Model (SON, 1991). The approach to investigate hidden costs used in this study was based on the theoretical foundation developed by Savall and Zardet (1991). The research results indicated the occurrence of hidden costs, mainly derived from malfunctioning related to rework, waiting time, high staff turnover, and stress. In addition, it was verified that among the most common hidden costs observed, rework, and waiting time, identified in virtually all sectors, are the ones that affect the most the proper functioning of the organization.
\end{abstract}

Keywords: Costs. Hidden costs. Service operations.

\section{Introdução}

O gerenciamento das informações e as tomadas de decisões estão diretamente ligados ao bom uso de um sistema de custeamento, adequado à realidade de cada empresa, bem como ao conhecimento da maioria dos custos que envolvem o processo produtivo.

\footnotetext{
${ }^{1}$ Programa de Pós-graduação em Engenharia de Produção, Universidade Federal da Paraíba - UFPB, Bloco G, Cidade Universitária, CP 5045, CEP 58051-970, João Pessoa, PB, Brasil, e-mail: pcesarpsilva@gmail.com; cosmosf@ct.ufpb.br
}

Recebido em 2/4/2009 - Aceito em 1/5/2011

Suporte financeiro: Nenhum. 
Nesse contexto, além dos custos já conhecidos, como os fixos e os variáveis, os diretos e os indiretos, surgem os custos ocultos como parte integrante da cadeia produtiva e/ou da prestação dos serviços. Sendo assim, é de fundamental importância o seu estudo e conhecimento para uma boa visualização do funcionamento da entidade como um todo.

A mensuração e a contabilização desses custos ainda não fazem parte das rotinas empresarias, mas estudos e teorias encontram-se sendo formulados em diversas academias, tais como visando o alcance do objetivo da verificação, reconhecimento e da mensuração dos custos ocultos do processo produtivo.

Neste artigo, procura-se aprofundamento em nível de verificação dos custos ocultos em operações de serviços. Tal estudo foi realizado em uma sociedade de economia mista com controle estatal.

Para tanto, realiza-se uma revisão de literatura, na qual se aborda a origem dos custos ocultos, a natureza dos fatores causadores e seus elementos. Em seguida, aportam-se custos ocultos em operações de serviços e as formas de tratamento dos custos ocultos. $\mathrm{O}$ item seguinte trata da metodologia utilizada para realização do estudo de caso, finalizando com a análise de resultado e considerações finais.

\section{Custos ocultos}

\subsection{Origem dos custos ocultos}

Segundo Savall e Zardet (1991), os custos ocultos são o resultado de uma interação permanente e complexa entre as estruturas da empresa e os comportamentos humanos, aqueles criados a partir do ortofuncionamento e dos disfuncionamentos da organização.

Acrescentam ainda que:

[...] se a origem dos custos ocultos reside nestas ligações complexas entres dois grupos de variáveis, um outro nível de observação é possível; com efeito, as interações entre as estruturas e os comportamentos se manifestam, concretamente, dentro de um certo nível de "territórios" ou de domínios do funcionamento da organização (SAVALL; ZARDET, 1991, p. 153) .

Para Sítima (2001), estes disfuncionamentos organizacionais são os desvios entre o funcionamento observado e aquele que é considerado racionalmente o mais desejado por parte da entidade.

Consoante o mesmo autor, os disfuncionamentos provocam os custos ocultos, assim designados porque, não sendo mensurados, não são reconhecidos contabilmente e, por conseguinte, dificilmente controláveis.

As falhas mencionadas acima têm as suas origens nos mais variados disfuncionamentos e nas mais diversas estruturas. Elas atingem os níveis emocional, material e organizacional dos profissionais e da entidade.

Os custos são objetos de estudo nos mais distintos setores da economia e por ser o setor que mais cresce na atualidade, o de serviço merece um destaque, não somente no tocante à sua representatividade na economia global, mas também como fonte de estudos e de descobertas em relação a este assunto.

A origem dos custos ocultos pode ser esquematizada por meio da Figura 1, na qual as disfunções são expressas visando o domínio da solução.

Essas famílias de variáveis explicativas podem ser detalhadas da seguinte forma:

- Operacionalização da estratégia: corresponde às técnicas, aos métodos e às práticas de transformação, de declinação e de tradução dos objetivos estratégicos da empresa em ações concretas para atingi-los;

- Condições de trabalho: reagrupa as condições físicas e as relações de trabalho;

- Organização do trabalho: compreende a repartição das funções internas da empresa, organização dos postos individuais de trabalho dentro de cada unidade, interdependência dos postos de trabalho e das atividades;

- Gestão do tempo: métodos de organização do tempo de trabalho individual e coletivo, repartição do tempo do indivíduo entre suas grandes atividades (preparação-execuçãocontrole, prevenção-regulação; funcionamento corrente, desenvolvimento).

Essas famílias representam, ao mesmo tempo, as variáveis explicativas e os domínios de solução das disfunções recenseadas, ou seja, elas oferecem, ao mesmo tempo, a explicação e a solução das disfunções conhecidas.

As disfunções, para Lima (1991), dão origem a custos, em geral ocultos, que são computados pela mensuração do impacto econômico associado aos fenômenos de absenteísmo, acidentes de trabalho, rotação do pessoal, qualidade dos produtos e produtividade direta.

\subsection{Natureza dos custos ocultos}

As disfunções geram custos para a empresa que, em geral, são ocultos e que afetam sua performance econômica.

Disfunção é, portanto, o ponto que, por convenção, vai ser assinalado como o diferencial entre o funcionamento esperado e o funcionamento atingido $\mathrm{e}$ que está na origem de um conjunto de custos ocultos.

Os custos ocultos são compostos por quatro principais componentes, sendo os três primeiros 


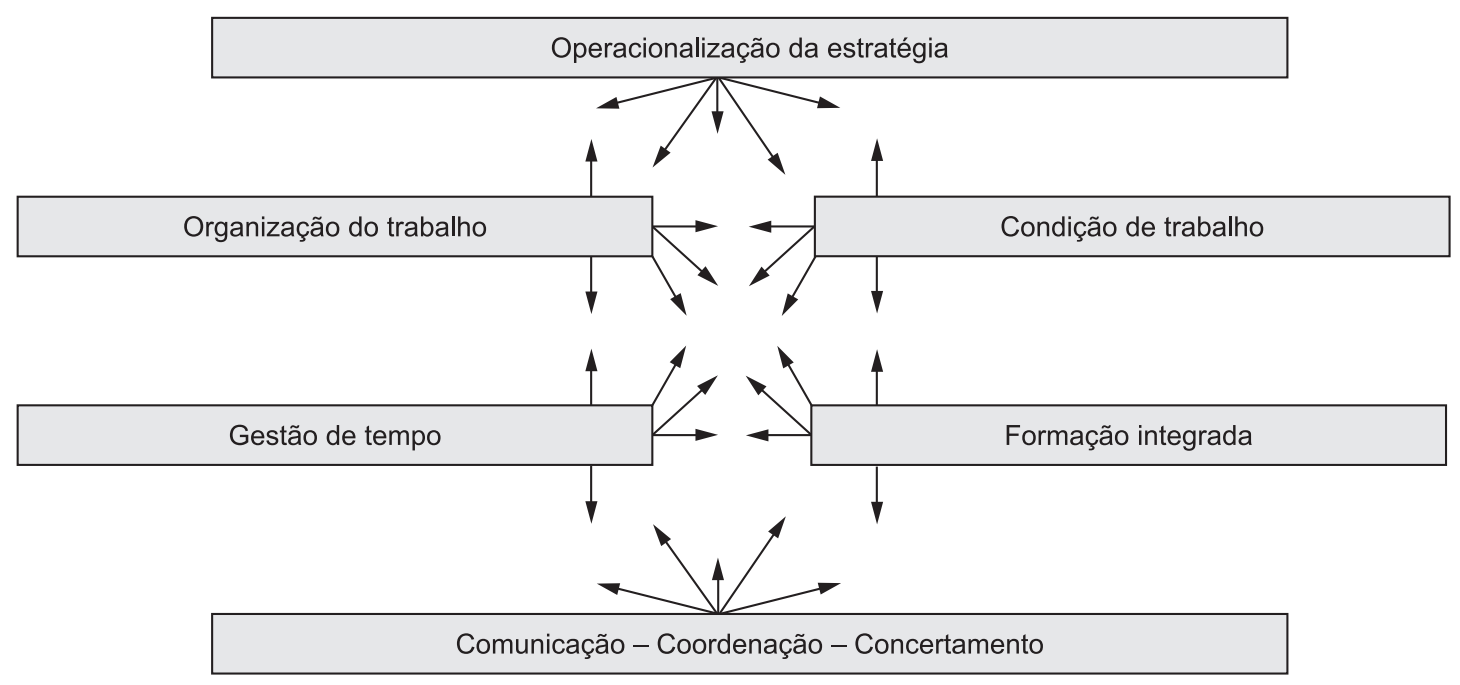

Figura 1. Famílias de variáveis que dão origem aos custos ocultos. Fonte: Adaptado de Savall e Zardet (1991).

formados pelo dispêndio que a empresa poderia evitar, ao menos parcialmente, se seu nível de disfunção fosse menos elevado. Trata-se dos sobressalários (ou salários de indenizações) pagos sem contrapartida em trabalho, remuneração dos tempos de regulação (dedicados a corrigir disfunções) ou ainda o sobreconsumo (consumo de materiais que seria inferior caso a empresa não tivesse que corrigir disfunções). $\mathrm{O}$ quarto componente dos custos ocultos é de natureza particular, pois não constitui propriamente uma carga, mas, sobretudo, um não produto ou uma perda de receitas de produção. Trata-se das ocasiões perdidas com relação a realizar e vender um produto ou serviço (custos de oportunidade).

Os custos ocultos, conforme a Figura 2, constituem-se, portanto, de sobrecargas (sobressalário, sobretempo e sobreconsumo) e de não produtos (não produção e não criação de potencial estratégico).

Segundo Lima (1991, 2006) e Silva (2008), essas sobrecargas e esses não produtos são identificados por rubricas de indicadores, tais como absenteísmo, acidentes de trabalho, rotação do pessoal, qualidade dos produtos (bens e serviços) e produtividade direta.

Estas observações derivam da Teoria SócioEconômica difundida por Savall e Zardet (1991), cujo grupo de trabalho, o ISEOR - Instituto de Sócio-Economia das Empresas e das Organizações, vem promovendo ampla difusão desta abordagem. Sua aplicação, como já mencionado, tem ocorrido em muitos países do mundo.

\subsection{Fatores causadores de custos ocultos}

As disfunções, que resultam da interação das estruturas organizacionais e dos comportamentos

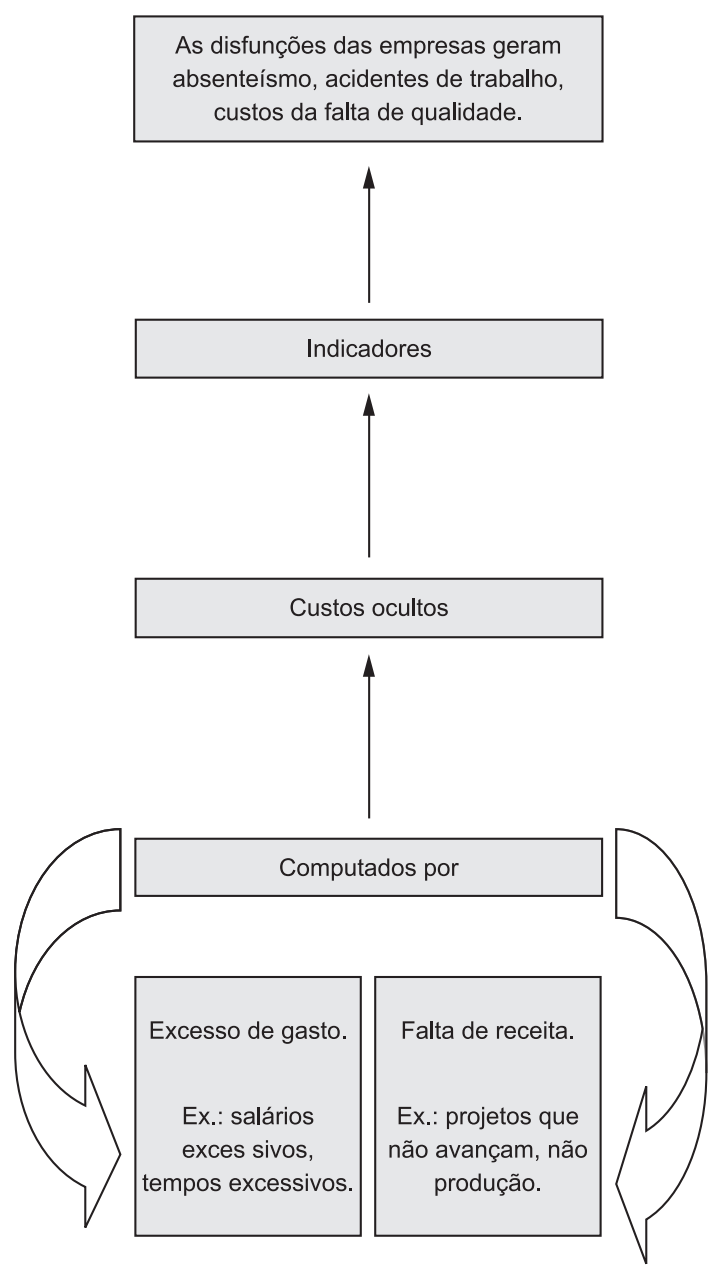

Figura 2. Componentes de custos ocultos. Fonte: Pesquisa direta (2007). 
das pessoas que as compõem, são as causadoras de custos, que geralmente são ocultos.

Os comportamentos são classificados em individuais, de grupos de atores, de categoria, de grupos de pressão e culturais. As estruturas podem ser de origens físicas, tecnológicas, organizacionais, demográficas e mentais. A interação entre esses comportamentos e essas estruturas forma os fatores causadores de custos ocultos.

\subsection{Elementos de custos ocultos}

Conforme apresenta Lima (1991), os elementos de custos ocultos podem ser classificados e decompostos como a seguir:

- Elementos de custo de absenteísmo: podem ser classificados em: tempo passado pelos supervisores, pela liberação da produção e pelos operários na realocação das tarefas, não produção, defeitos eventuais de qualidade, sobrecustos salariais (horas suplementares, pessoal adicional), não cobertura dos custos fixos da estrutura, subprodutividade dos operários substituintes;

- Elementos de custos de acidentes de trabalho: estes podem ser classificados em custos diretos, salários de ausente substituído, tempo passado pelos supervisores na regulação da perturbação, não produção (parada de máquinas); perturbação do ambiente de trabalho, primeiros socorros. Se o acidente for cobrado adicionalmente pela previdência social: oferecem ainda aumento de cotização da empresa à previdência social; procedimentos administrativos de declaração à previdência social;

- Elementos de custos de rotação de pessoal: podem ser classificados em complemento da amortização do investimento em recursos humanos realizado sobre operários que partem; custo de recrutamento, custo de formação, procedimentos de partida, perturbações da atividade, investimento em recursos humanos efetuados sobre o substituinte;

- $O$ custo de não qualidade: podendo ser decomposto da seguinte forma: custo comercial da devolução e da troca do lote defeituoso (custo do tempo passado a resolver o litígio em lugar de realizar uma nova venda - tempo de regulação mais tempo de não produção), custo de produção dos retoques, das reciclagens, de disposição de refugos (custo do tempo passado efetuando os retoques, consumo de material e energia nesse sentido, perda de produção durante o tempo que se passa resolvendo esses litígios ao invés de produzir um novo lote faturável - tempo de regulação mais sobreconsumo mais não produção);

- Os custos ligados à produtividade direta: são decompostos da seguinte forma: sobreconsumo de matérias-primas e de material secundário, não produção representada por uma diferença a ganhar, ligada seja às paradas de máquinas, seja a uma menor produtividade do trabalho humano (habilidade, rapidez), seja a problemas de aprovisionamento e de ritmo entre postos de trabalho.

\section{Custos ocultos em operações de serviços}

Na opinião de Santos (2003), a maioria das empresas de serviços, ao contrário, nunca teve a necessidade de medir os custos de seus produtos ou clientes e funcionou por décadas sem sistemas de custos. Evidentemente, não sem sistemas financeiros. As empresas de serviços gerenciavam operações por meio do controle orçamentário de centros de responsabilidade. As empresas eram organizadas por departamentos funcionais, os orçamentos definidos para cada departamento ou centro de responsabilidade e o desempenho financeiro medido e gerenciado pela comparação dos resultados reais com os valores orçados.

$\mathrm{Na}$ verdade, as empresas de serviços tinham sua própria versão dos sistemas de controle operacional, embora não utilizassem muito o orçamento flexível, pois quase todos os custos de uma empresa de serviços vêm de recursos comprometidos antes do uso; ou seja, são custos fixos a curto prazo.

Assim, embora as empresas de serviços fossem frequentemente tão complexas e diversificadas quanto as indústrias, os gerentes não conheciam os custos dos serviços produzidos e fornecidos, nem o custo de servir a diferentes tipos de clientes.

Ainda segundo Santos (2003), durante décadas, essa falta de informações precisas sobre produtos e clientes não foi uma preocupação, pois a maioria das empresas de serviços operava em mercados benignos, não competitivos. Muitas empresas de serviços, até recentemente, eram altamente regulamentadas. Os legisladores estabeleciam preços suficientes para cobrir os custos operacionais de empresas ineficientes.

Como até pouco tempo as empresas prestadoras de serviços não apuravam os seus custos por meio dos STCs - Sistemas Tradicionais de Custeio, porque tinham legislação própria, elaborada de maneira a cobrir seus custos operacionais, o estudo dos custos ocultos nessas organizações pode se mostrar de grande valia, ao passo em que ele identificará onde existem 
as disfunções que empatam o crescimento e a boa qualidade da prestação dos serviços.

Segundo Lima (1991), o método de análise socioeconômico (estudo dos custos ocultos) foi aplicado até o momento em mais de cem organizações de todo o tipo e tamanho (de 20 a 4500 pessoas), em vários setores econômicos (indústria, serviços públicos, hospitais, bancos, escritórios de consultoria), e em situações econômico-financeiras favoráveis ou não, principalmente na França, mas também em outros países.

A média de custos ocultos encontrada em estudos realizados pelas intervenções socioeconômicas realizadas é de 12.000 dólares por pessoa e por ano. As intervenções realizadas mostram que, do total de custos ocultos, cerca de $30 \%$ a $50 \%$ podem ser reduzidos; o restante dos custos, inerentes à vida da organização, são considerados como fisiológicos.

Como visto anteriormente, a parcela de custos ocultos por pessoa e por ano é bastante relevante e há uma grande porcentagem de custos ocultos que podem ser melhorados ou evitados dentro das organizações. Ao estudar, mensurar e buscar soluções para a problemática das disfunções nas organizações, busca-se superávits financeiros, objetivando o aperfeiçoamento da performance econômica.

\section{Formas de tratamento dos custos ocultos}

Pelo não tratamento e utilização de custos ocultos em Sistemas Tradicionais de Custos - STCs, é que os já citados pesquisadores do ISOER, por meio do estudo da origem dos custos ocultos, sugerem o método de análise socioeconômico como forma de constatar e tratar tais custos.

Este modelo fundamenta-se na construção de uma teoria particular sobre o funcionamento das empresas e organizações, desenvolvendo ferramentas de gestão capazes de auxiliar a melhoria de sua eficiência social e econômica.

Segundo Lima (1991), os conceitos da metodologia socioeconômica estruturam-se em três dimensões:

- A dimensão das decisões políticas, que contempla a estratégia empresarial, as regras do jogo explicitadas aos atores das empresas e organizações que servirão de terreno experimental, a definição dos parâmetros dos contratos de atividade periodicamente negociáveis e a política social;

- A dimensão das ferramentas de trabalho, que contempla o contrato de atividades periodicamente negociável (CAPN), o painel de gestão socioeconômica, a matriz de competências, a matriz de autoanálise da gestão do tempo e o plano de ações prioritárias;
- A dimensão do processo de intervenção-pesquisa socioeconômica, que contempla o diagnóstico, o projeto de melhoramento, a operacionalização do projeto e sua avaliação.

Como visto anteriormente nas dimensões do modelo socioeconômico e baseando-se no modelo teórico desenvolvido por Savall e Zardet (1991), as ferramentas para tratamento dos custos ocultos são:

- Os contratos de atividades periodicamente renegociáveis (CAPN), que visam modificar a dialética conflito-cooperação no seio da organização, de forma a aumentar a zona de convergência dos atores: direção, supervisão, pessoal de base, representação do pessoal;

- O painel de gestão socioeconômica, que fornece a cada membro da empresa que tenha responsabilidades hierárquicas, que seja, por conseguinte, copiloto da operacionalização de estratégia empresarial, um painel de pilotagem adaptado às suas funções e à sua zona de responsabilidades;

- A matriz de competências, que tem como objetivos o melhoramento da adequação formação-emprego; observação dos dois principais critérios da qualidade e da eficácia coletiva de um serviço: as operações vulneráveis (falta de competências disponíveis) e de dosagem, a polivalência (a especialização de cada pessoa é fonte de seu interesse no trabalho); e a detecção das necessidades de formação efetiva de cada assalariado (um plano de formação personalizado de cada unidade);

- A matriz de autoanálise de gestão de tempo, que foi criada para identificar as tarefas realizadas pelo pessoal durante a jornada de trabalho e as disfunções associadas à natureza das tarefas executadas e à correspondente alocação de tempo;

- O plano de ações prioritárias (PAP) é uma ferramenta que, na fase operacional, corresponde à operacionalização dos objetivos estratégicos da organização. A fase conceitual corresponde aos procedimentos que permitem a exposição dos objetivos estratégicos a partir de diagnósticos das disfunções com relação ao ambiente externo.

Segundo Lima (1991), as ações prioritárias para uma operacionalização da estratégia eficaz possuem as seguintes características: uma compreensão generalizada pelos atores da organização; uma formulação bem concreta e uma planificação em termos do tempo necessário à sua realização.

Acrescenta-se que a literatura existente sobre custos ocultos encontra-se em fase de elaboração. 
Sendo assim, não é possível verificar as formas de tratamento dadas pelo setor contábil das organizações. É sabido que, como foi anteriormente explicitado, os Professores Savall e Zardet do ISEOR, por meio de sua Teoria Sócio-Econômica da Empresa, utilizam-se de metodologias capazes de verificar e, quando muito, eliminar os custos ocultos gerados nas organizações.

\section{Metodologia}

Com a finalidade de atingir os objetivos deste artigo, foi aplicado um questionário semiestruturado e visitas in loco, visando à obtenção de dados para suportar a análise e as considerações acerca dos custos ocultos existentes na organização, objeto deste estudo.

O questionário semiestruturado foi direcionado ao levantamento dos custos ocultos referentes à espera, movimentação inútil, sobressalários, sobreconsumo, retrabalho, acidente de trabalho, absenteísmo, ociosidade e litígios, objetivando a verificação da existência deles no processo da prestação de serviço da organização.

Foram realizadas entrevistas com colaboradores da organização, como também conversas informais acerca dos elementos de custos ocultos mencionados anteriormente, com a finalidade de obter o suporte necessário ao estudo de caso, análise de resultados e considerações finais.

\subsection{Variáveis de investigação}

As variáveis investigadas estão descritas a seguir, conforme apresentadas no Quadro 1. Essas variáveis são produtos do rastreamento bibliográfico realizado. Elas foram investigadas conforme os procedimentos descritos posteriormente.

A investigação das variáveis acima expostas deu-se por meio do framework proposto por Lima (2006), com adaptações necessárias ao setor de serviços. Para tanto, utilizou-se a matriz 5Q1C, para fins de investigação das variáveis listadas no Quadro 1. A matriz 5Q1C encontra-se ilustrada na Figura 3.

\subsection{Framework em custos ocultos}

O framework que se descreve na Figura 4 foi aplicado na indústria manufatureira e serviu de base para elaboração de um framework destinado ao setor da prestação de serviços, para o atendimento aos objetivos de pesquisa deste artigo.

Segundo o autor, a primeira coluna contém um check-list de entrada destinado ao rastreamento (fase I) dos elementos de custos ocultos na indústria têxtil. O check-list é produto da pesquisa realizada e está composto de 10 (dez) itens, a saber: set-up, retrabalho, estoque, ociosidade, perdas, litígios, acidentes de trabalho, atestado médico, inspeção e movimentação inútil.
O check-list proposto anteriormente sofreu adaptações para sua aplicação no setor de serviços.

A segunda coluna destina-se à identificação das fontes geradoras dos elementos de custos ocultos, correspondendo aos setores e/ou postos operatórios em que ocorre a incidência dos custos ocultos.

A terceira coluna diz respeito a uma outra fase do framework proposto pelo autor. Destina-se à apuração dos elementos de custos ocultos, especificamente à forma de contabilização (frequência). Esta etapa é necessária, pois relaciona a ocorrência do custo com sua respectiva frequência, o que permite a monetarização de seus valores e, por conseguinte, o reconhecimento dos montantes por eles gerados.

Finalmente, a quarta coluna refere-se aos marcos teóricos de análise dos elementos de custos ocultos, extraídos do processo de levantamento e apreciação da literatura disponível. Trata-se de modelos teóricos de compreensão, acerca do comportamento e lógica de custos ocultos, em processos operacionais e de manufatura.

Todas as etapas acima especificadas foram aplicadas em uma indústria manufatureira. Necessário se faz a adaptação delas para aplicação no setor de serviços. A adaptação mencionada está demonstrada na Figura 5.

O framework acima é a representação da adaptação do fremework utilizado por Lima (2006), em um estudo de caso em uma indústria têxtil, para o estudo de caso realizado neste artigo.

\section{Estudo de caso e análise de resultados}

A empresa objeto deste estudo é uma prestadora de serviços, com sede na cidade de João Pessoa PB - Brasil, uma sociedade de economia mista com controle estatal e seu principal objetivo é administrar dois Fundos de Desenvolvimento e os Distritos Industriais do Estado da Paraíba - Brasil.

Quadro 1. Variáveis de investigação.

\begin{tabular}{|cc|}
\hline Variáveis & Vetores \\
\hline Custos ocultos & Espera \\
Movimentação inútil \\
Sobressalários \\
Sobreconsumo \\
Retrabalho \\
Acidente de trabalho \\
Absenteísmo \\
Ociosidade \\
Litígios \\
\hline
\end{tabular}

Fonte: Pesquisa direta (2007). 

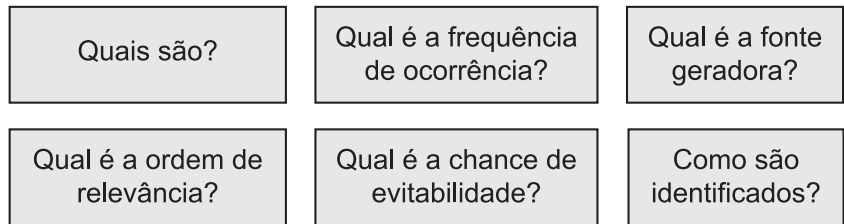

Figura 3. Matriz 5Q1C. Fonte: Adaptado de Lima (2006).

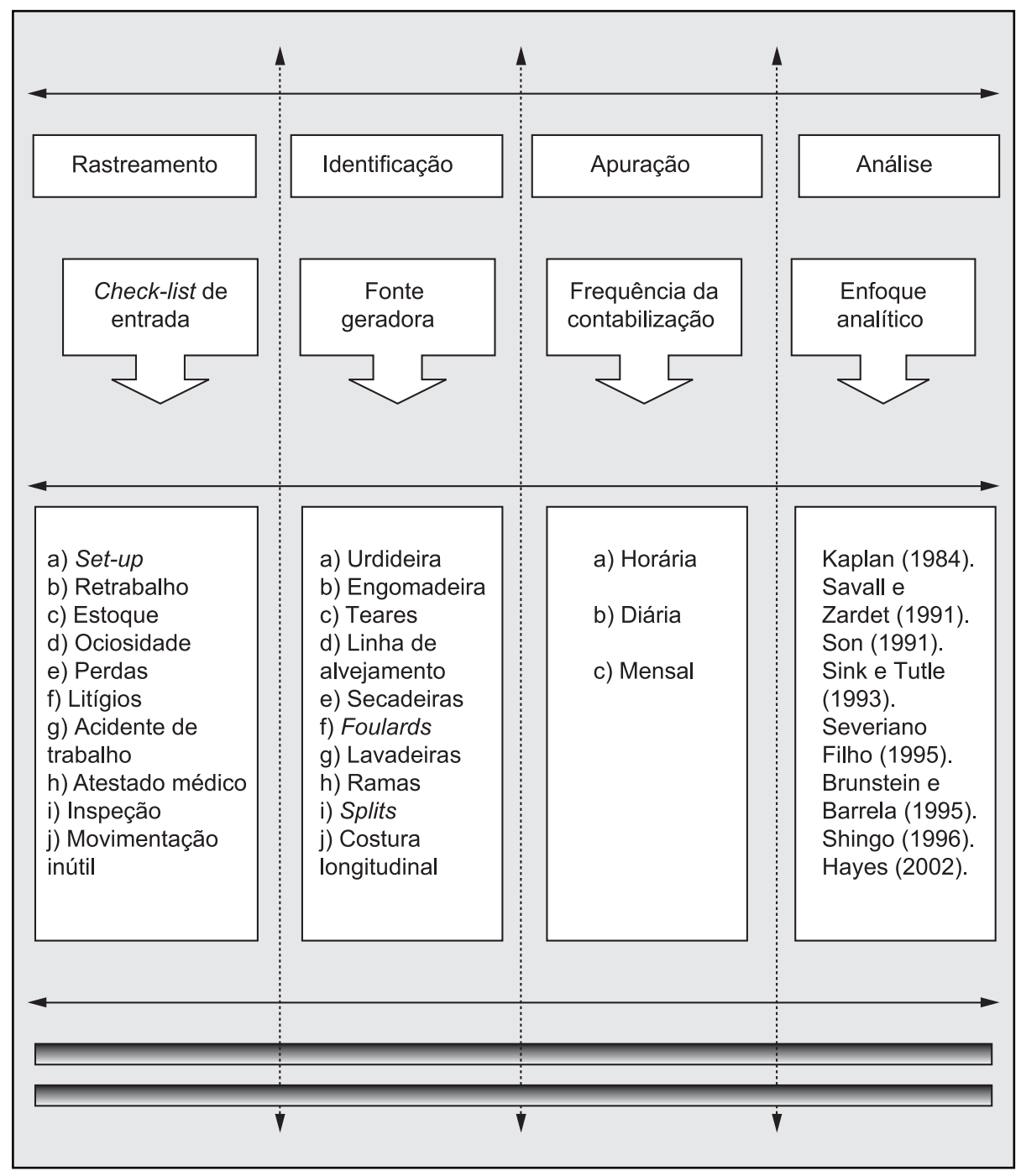

Figura 4. Framework: rastreamento, identificação, apuração e análise dos custos ocultos na indústria têxtil. Fonte: Adaptado de Lima (2006).

Ao realizar o estudo de caso, ficou clara a existência dos custos ocultos, como apresentado na Tabela 1.

Analisando a Tabela 1, se verifica que, dos 9 elementos de custos ocultos estudados no processo, há a incidência de 5 e a não incidência de 4 , o que em porcentagem, a incidência corresponde a $56 \%$ do total de custos ocultos rastreados.

Essa porcentagem mostra uma significativa incidência de disfuncionamentos, ou seja, uma interação permanente e complexa entre as estruturas da empresa e dos comportamentos humanos, gerando assim os custos ocultos apontados na Tabela 1 .

Da análise da Tabela 1, pode-se inferir em relação à não incidência dos custos ocultos, que os sobressalários, os sobreconsumos, o acidente de trabalho e os litígios não são encontrados frequentemente na organização estudada. Isto se deve ao fato, por exemplo, em relação ao elemento de custo oculto vinculado aos acidentes de trabalho, que a empresa ora estudada é uma prestadora de serviços com planta altamente 


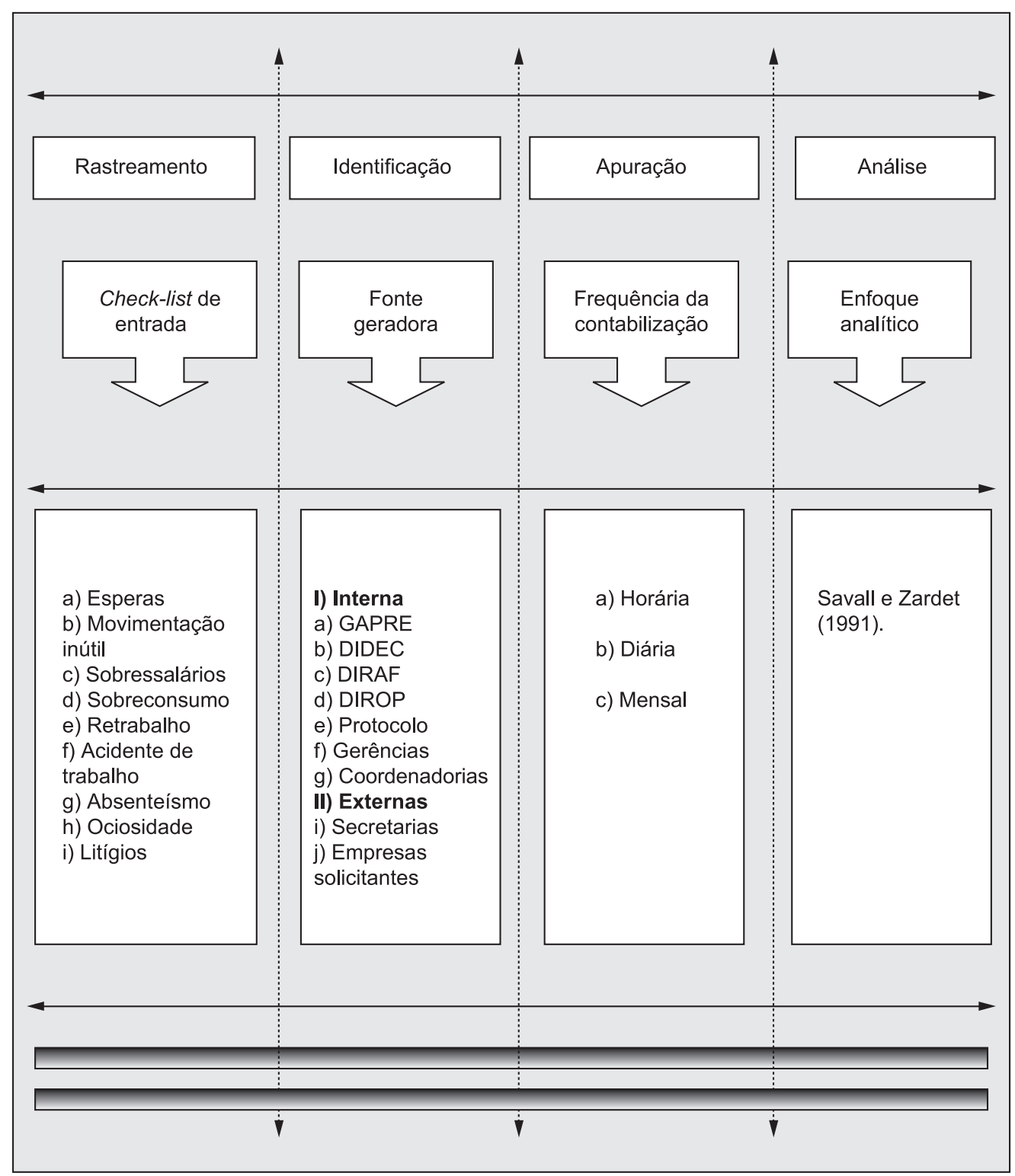

Figura 5. Framework adaptado para rastreamento, identificação, apuração e análise dos custos ocultos nos serviços. Fonte: Pesquisa direta (2007). GAPRE - Gabinete da Presidência; DIDEC - Diretoria de Desenvolvimento Econômico; DIRAF Diretoria Administrativa e Financeira; DIROP - Diretoria de Operações.

Tabela 1. Elementos de custos ocultos do processo.

\begin{tabular}{lcc}
\hline $\begin{array}{c}\text { Elementos de } \\
\text { custos ocultos }\end{array}$ & Incidência & $\begin{array}{c}\text { Não } \\
\text { incidência }\end{array}$ \\
\hline Esperas & $\mathrm{X}$ & \\
Movimentação inútil & $\mathrm{X}$ & \\
Sobressalários & & $\mathrm{X}$ \\
Sobreconsumo & $\mathrm{X}$ & $\mathrm{X}$ \\
Retrabalho & & $\mathrm{X}$ \\
Acidente de trabalho & $\mathrm{X}$ & \\
Absenteísmo & $\mathrm{X}$ & \\
Ociosidade & & $\mathrm{X}$ \\
Litígios & & \\
\hline
\end{tabular}

Fonte: Pesquisa direta (2007). convencional, não oferecendo grandes riscos aos seus colaboradores.

Verificando os custos ocultos incidentes na organização, o retrabalho acontece, porque a empresa não possui um fluxograma definido dos procedimentos processuais, ou seja, o fluxo dos processos que dão entrada no protocolo não é contínuo, havendo muitas movimentações desnecessárias ao processo. $\mathrm{O}$ retrabalho também acontece porque as gerências não trabalham de forma integrada com o constante compartilhamento de informações e ainda porque as atribuições e funções dessas gerências não são bem definidas. 
As esperas são provocadas pela alta burocracia existente no serviço público. Na organização são verificadas em quase todas as etapas do processo de prestação de serviço. Isto eleva os custos não computados na contabilidade tradicional da empresa.

Observou-se ainda, que os disfuncionamentos existentes reduzem sobremaneira o desempenho da organização, prejudicando suas taxas de produtividade, que quase sempre sequer são medidas. É importante observar que, os elementos de custos ocultos estudados, promovem a medição do desempenho da empresa, permitindo a indicação de suas taxas de improdutividade. A mensuração e controle destes índices são fundamentais para a alavancagem do sucesso desejado.

\subsection{Rastreamento dos custos ocultos do processo}

O rastreamento dos custos ocultos do processo determina qual a incidência ou não incidência desses custos, a frequência, a fonte geradora, a ordem de relevância, o grau de evitabilidade e como são identificados tais custos.

Em relação à fonte geradora, por exemplo, pode-se afirmar que tem duas origens: uma interna e outra externa, de acordo com a matriz 5Q1C e o framework adaptado para o setor de serviços.

As de origem interna são as que acontecem dentro do próprio posto de trabalho, ou seja, dentro do Sistema de Crédito, como por exemplo, GAPRE, DIRAF, DIDEC, DIROP, protocolo, gerências e coordenadorias, enquanto que as esperas, além de origem interna, também possuem origens externas, como por exemplo: Secretarias de Estado, empresas solicitante e agente financeiro.

Tais procedimentos são verificados logo a seguir, no estudo do comportamento de custos ocultos do processo estudado, verificando-se o fato gerador, a periodicidade, a ordem de relevância, a ordem de evitabilidade e a identificação dos custos ocultos do processo estudado.

\subsection{Comportamento de custos ocultos do processo estudado}

A determinação deste item da apresentação e análise de resultado objetiva à identificação do fato gerador, a periodicidade, a ordem de relevância, a ordem de evitabilidade, as formas de identificação dos custos ocultos e o impacto financeiro gerado por eles no resultado operacional do fundo por meio do processo estudado.

\subsubsection{Fato gerador}

Conforme mencionado no item 6, os custos ocultos existentes no processo são: esperas, movimentação inútil, retrabalho, absenteísmo e ociosidade, que têm seus fatos geradores determinados no Quadro 2.

De maneira geral, muitos dos fatores geradores de custos ocultos expressos no Quadro 2, anteriormente, se devem ao fato do órgão ser uma entidade pública, inexistindo assim, um maior controle quanto ao acesso dos funcionários ao trabalho, dos meios e modos para desenvolvimento das atividades, bem

Quadro 2. Fato gerador de custos ocultos do processo.

\begin{tabular}{|c|c|}
\hline Elementos de custos ocultos & Fato gerador \\
\hline Esperas & $\begin{array}{l}\text { Ocasionadas principalmente pela entrega incompleta de documentação quando } \\
\text { da apresentação do projeto, por falhas nos equipamentos de informática, por } \\
\text { terceiros, ou seja, por outros setores que demoram a entregar determinados dados. }\end{array}$ \\
\hline Movimentação inútil & $\begin{array}{l}\text { Ocasionadas pela falta de um fluxo processual correto, } \\
\text { pelo desencontro de informações, falhas de equipamentos } \\
\text { eletrônicos, incorreto entendimento de despachos. }\end{array}$ \\
\hline Retrabalho & $\begin{array}{l}\text { Pela ausência de treinamentos, pela falta de capacitação técnica, pelo incorreto } \\
\text { entendimento dos despachos efetuados, por falha nos equipamentos, pela falta de } \\
\text { integração entre determinados setores, pela falta de um adequado organograma } \\
\text { funcional, pela ausência de um fluxo processual correto. }\end{array}$ \\
\hline Absenteísmo & $\begin{array}{l}\text { Pela ausência ao posto operatório em longos períodos, ou em períodos que } \\
\text { não justifiquem a ausência, como também pela falta de controle do ponto, pela } \\
\text { inexistência da verificação da presença dos funcionários aos postos de trabalho. }\end{array}$ \\
\hline Ociosidade & $\begin{array}{l}\text { Pela incapacidade técnica, pela falta de organização dos pensamentos, } \\
\text { pela falta de controle dos chefes, não exigindo dos funcionários, } \\
\text { pela falta de compromisso do funcionário com suas responsabilidades, } \\
\text { por longos períodos de férias e licenças. }\end{array}$ \\
\hline
\end{tabular}

Fonte: Pesquisa direta (2007). 
Tabela 2. Periodicidade dos custos ocultos do processo.

\begin{tabular}{cc}
\hline Elementos de custos ocultos & Quantidade (em dias) \\
\hline Esperas & 15 \\
Movimentação inútil & 10 \\
Retrabalho & 8 \\
Absenteísmo & 10 \\
Ociosidade & 5 \\
\hline
\end{tabular}

Fonte: Pesquisa direta (2007).

como falta de inovação, adequação e adaptação aos novos modelos de mercados.

\subsubsection{Periodicidade}

A existência dos custos ocultos rastreados no processo facilmente indica para um recorrente período de acontecimento, em que pode com prontidão, ser identificado de acordo com os elementos de custos ocultos encontrados. Isto pode ser observado na Tabela 2.

A aferição da quantidade de dias da Tabela 2 demonstra a quantidade de dias do mês que são inutilizados pelos efeitos dos elementos de custos ocultos encontrados no processo, ou seja, esses dias são considerados de pouco desempenho ou improdutivos.

A análise da Tabela 2, permite afirmar-se que é considerável a medição dos acontecimentos dos custos ocultos encontrados no processo, pois como visto, as esperas consomem 15 dias, sendo essa quantidade bastante relevante à qualquer processo de uma organização. A movimentação inútil e o absenteísmo também demonstram que deve haver um maior controle acerca dos comportamentos dos colaboradores, visando a uma eliminação ou diminuição, já que estes consomem mensalmente cerca de 10 dias do processo.

\section{Considerações finais}

O estudo realizado não é estanque, há muito que se descobrir na área de custos ocultos, seja ele direcionado para o setor dos serviços, da indústria, da agricultura e outros.

Ficou evidente neste estudo que a organização com medidas simples, tais como, definição de fluxo de processos, coordenação da integração entre os setores e facilitação da criação de um sistema de informação, já eliminaria em sua quase totalidade os custos ocultos existentes na sua prestação de serviços.

Medidas são necessárias visando à verificação, reconhecimento e mensuração dos custos ocultos presentes nos processos da prestação de serviço, como também nos processos industriais, objetivando sua contabilização, para auxílio às tomadas de decisões gerenciais e à eliminação dos elementos de custos ocultos presentes naqueles processos.

$\mathrm{Na}$ conclusão da pesquisa, é importante ressaltar que, da experiência do estudo realizado, em se tratando de um caso examinado, seus resultados não podem ser conclusivos e/ou generalizados.

A utilização do framework e da matriz 5Q1C proporcionou, com qualidade satisfatória, o rastreamento dos custos ocultos existentes no processo, o que sugere, como a própria matriz propõe, trabalho no sentido de buscar quais são os custos ocultos, onde são gerados, a fim de se buscar impedir a sua existência no processo.

Os custos ocultos encontrados no processo, em sua grande maioria, poderiam ser evitados com medidas que não gerariam grandes dispêndios financeiros para a organização, como por exemplo, o custo do absenteísmo e da ociosidade, que poderiam simplesmente ter suas influências diminuídas se a organização efetuasse maior controle sobre seus recursos humanos.

\section{Referências}

LIMA, C. E. B. Custos ocultos em uma planta tecnologicamente avançada do sub-setor de tecelagem da indústria têxtil: comportamento, lógica e framework. 2006. Tese (Doutorado em Engenharia de Produção)Universidade Federal da Paraíba, João Pessoa, 2006.

LIMA, M. A. A. A estrutura e as ferramentas da intervençãopesquisa sócio-econômica nas empresas e demais organizações. Revista de Administração de Empresas, p. 21-30, 1991.

SANTOS, J. S. Custos ocultos no processo de instalação de elevadores OTIS VF1. 2003. Monografia (Especialização em Engenharia de Produção)-Universidade Federal da Paraíba, João Pessoa, 2003.

SAVALL, H.; ZARDET, V. Maitriser lês coûts eat lês perfomances cachês. Paris, 1991.

SILVA, P. C. P. Rastreamento dos Custos Ocultos em Operações de Serviços: estudo de caso em uma sociedade de economia mista com controle estatal na Paraíba. 2008. Dissertação (Mestrado em Engenharia de Produção)-Universidade Federal da Paraíba, João Pessoa, 2008.

SÍTIMA, B. F. B. A contabilização dos custos ocultos na empresa: uma abordagem aos custos com o absentismo numa central termoeléctrica. Lisboa: ISCTE, 2001.

SON, Y. H. A framework for modern manufacturing economics. International Journal of Production Research, v. 29, n. 12, 1991. http://dx.doi. org/10.1080/00207549108948098 